\title{
Strategi Komunikasi Pemasaran Terpadu Colourfun Booth dalam Mempertahankan Konsumen di Era New Normal
}

\author{
Evie Christina, Yugih Setyanto \\ eviechristina77@gmail.com,yugihs@fikom.untar.ac.id \\ Fakultas Ilmu Komunikasi Universitas Tarumanagara
}

\begin{abstract}
In the new normal era, people are becoming more selective in spending on household expenses, transportation, and other necessities. In fact, not a few companies have experienced a decline in population, drastically decreasing workers, so that they have to go out of business. Colourfun Booth is a service industry that provides photo booth services or photo printing services at various events. In keeping consumers in the new normal era, Colourfun Booth develops a marketing communication strategy by bringing together several communication elements such as advertising, direct response, sales promotion, including social media Instagram and Facebook. This relationship turns out to be a link between brands and consumers to generate consumer loyalty to the brand.
\end{abstract}

Keywords: colourfun booth, integrated marketing communication, new normal

\begin{abstract}
Abstrak
Di era new normal, masyarakat menjadi lebih selektif dalam mengeluarkan biaya rumah tangga, transportasi, hingga kebutuhan lainnya. Sehingga, tak sedikit perusahaan yang mengalami penurunan kapasitas produksi, pengurangan kapasitas pekerja, hingga harus gulung tikar. Colourfun Booth merupakan industri jasa yang memberikan layanan jasa photo booth atau jasa cetak foto pada berbagai acara-acara. Dalam menjaga konsumen di era new normal, Colourfun Booth mengembangkan strategi komunikasi pemasaran dengan cara menyatukan beberapa elemen komunikasi seperti periklanan, respon langsung, promosi penjualan, termasuk media sosial Instagram dan Facebook. Hubungan tersebut ternayata mampu menjadi pengait antara merek dengan konsumen untuk membangkitkan loyalitas konsumen terhadap merek.
\end{abstract}

Kata Kunci: colourfun booth, kenormalan baru, komunikasi pemasaran terpadu

\section{Pendahuluan}

Persaingan bisnis di era globalisasi dewasa ini menjadi semakin ketat dalam mengunggulkan usahanya masing-masing terutama di era New Normal. Di era New Normal banyak perusahaan yang mengalami penurunan kapasitas produksi, pengurangan kapasitas pekerja, dan tak jarang yang harus gulung tikar. Akibatnya pemilik usaha berusaha beradaptasi dengan perubahan-perubahan yang terjadi dan mengembangkan strategi komunikasi pemasaran yang tepat agar usahanya tetap dapat berdiri dan unggul dalam bersaing.

Seiring dengan perkembangan zaman, keinginan konsumen semakin meningkat. Sehingga, kepuasan konsumen bukan hanya dinilai dari hasil jasa yang diberikan tetapi juga fasilitas pendukung yang tersedia. Maka perusahaan perlu menetapkan dan mengembangkan strategi komunikasi pemasaran yang baru. Komunikasi pemasaran mempermudah perusahaan dalam memberikan informasi, 
membujuk, dan mengingatkan konsumen baik secara langsung maupun tidak langsung mengenai produk atau jasa yang ditawarkan.

Banyaknya usaha di dalam bidang photobooth yang dapat kita temui seperti Yuk Photo Booth, Colourfun Booth, Mostache Photo Booth, Narema Photo Booth, Lol Photo Booth, dan lainnya. Colourfun Booth merupakan industri jasa yang memberikan layanan jasa photobooth atau jasa cetak foto secara langsung pada acara-acara seperti ulang tahun, pernikahan, graduasi, reuni, perusahaan dan sebagainya.

Colourfun Booth berdiri sejak 2012 yang berpusat di Joglo, kota Jakarta Barat. Terbentuknya Colourfun Booth ini didukung oleh fenomena selfie pada saat itu yang tidak dapat terlepas dari perkembangan teknologi yang begitu pesat terutama di media sosial.

Colourfun Booth hadir karena memahami kebutuhan konsumen yaitu mempermudah proses foto dan cetak foto secara langsung. Selain itu, segmentasi pasar Colourfun Booth yaitu berusia 20-45 tahun dan secara garis besar penggunaan jasa photobooth ini untuk acara pernikahan. Sedangkan segmentasi geografis pasar sebagian besar berada di Jakarta tetapi tidak menutup kemungkinan untuk ekspansi di daerah lain karena tergantung request dari konsumen.

Dengan harga yang terjangkau Colourfun Booth tentu memberikan pelayanan yang terbaik dengan hasil foto yang memuaskan dan fasilitas pendukung yang tersedia. Colourfun Booth berusaha melakukan perencanaan pemasaran agar antarelemen komunikasi dapat berjalan dengan baik.

\section{Landasan Teori}

Komunikasi pemasaran memiliki peranan yang sangat penting karena komunikasi pemasaran berfungsi sebagai alat promosi yang efektif bagi Colourfun Booth untuk berkomunikasi dengan masyarakat. Komunikasi pemasaran merupakan cara perusahaan untuk memberikan informasi, membujuk, dan mengingatkan konsumen baik secara langsung maupun tidak langsung mengenai produk dan jasa dari perusahaan tersebut (Kotler dan Keller, 2012:498).

Secara spesifik, Komunikasi pemasaran terpadu adalah cara yang memiliki dua peranan yaitu menciptakan dan memelihara hubungan yang baik antara Colourfun Booth dengan konsumen dengan mengatur dan memengaruhi secara diplomatis seluruh pesan yang diberikan. Hal ini berfungsi untuk menggerakkan konsumen sesuai keinginan perusahaan yaitu melakukan kegiatan membeli.

Dengan demikian, penerapan komunikasi pemasaran terpadu yang tepat akan mempermudah pesan yang disampaikan Colourfun Booth kepada konsumen dengan tepat sasaran dan diterima dengan baik. Hal ini dapat menyebabkan peningkatan pembelian. Pada intinya, komunikasi pemasaran terpadu memadukan seluruh bauran komunikasi sehingga dapat bekerja bersama-sama secara harmonis. Sementara menurut Kotler \& Amstrong (2012), bauran promosi terdiri atas:

A. Iklan: Dapat meningkatkan citra bagi produk atau jasa Colourfun Booth dan dapat meningkatkan penjualan dengan cepat. Iklan dapat efisien menjangkau pembeli yang tersebar secara geografis.

B. Public Relations: Dalam mempromosikan, Public Relations tidak hanya fokus pada manfaat dan fitur produk tetapi juga fokus pada nilai-nilai perusahaan secara keseluruhan. Nilai-nilai perusahaan ini akan menciptakan persepsi masyarakat terhadap Colourfun Booth atau yang dikenal dengan sebutan citra perusahaan. Citra perusahaan dianggap sebagai kesan yang tertanam di dalam benak masyarakat mengenai produk atau jasa dari Colourfun Booth. 
C. Personal Selling: Hubungan secara langsung dengan calon konsumen potensial yang bertujuan untuk menjelaskan detail produk, menjawab pertanyaan dan memperoleh pemesanan.

D. Promosi Penjualan: Kegiatan-kegiatan yang dilakukan demi mendorong konsumen mencoba dan membeli produk atau jasa dari Colourfun Booth seperti potongan harga.

E. Pemasaran Langsung: Kegiatan pemasaran ini dilakukan Colourfun Booth secara langsung kepada konsumen dan calon konsumen potensial melalui sosial media dan e-mail untuk berkomunikasi secara langsung.

F. Event and Experiences: Acara dan pengalaman memberikan banyak keuntungan karena Colourfun Booth memiliki karakteristik.

\section{Metode Penelitian}

Peneliti menggunakan pendekatan penelitian kualitatif pada penelitian ini Menurut Tohirin (2013:2), Penelitian kualitatif merupakan penelitian yang berupaya membangun gambaran individu secara detail kemudian dibentuk menjadi kata-kata, gambaran secara menyeluruh dan juga rumit. Peneliti menggunakan pendekatan penelitian kualitatif untuk menjelaskan strategi yang dilakukan Colourfun Booth dalam menjaga konsumen di era new normal yang diuraikan ke dalam bentuk katakata dan gambaran secara menyeluruh.

Dalam penelitian ini, peneliti menggunakan metode studi kasus untuk menggambarkan suatu permasalahan menurut pandangan Public Relations. Dapat berupa peristiwa, orang, program, insiden kristis atau unik. Seperti bagaimana strategi yang dilakukan Colourfun Booth dalam menjaga konsumen di era new normal. Maka dapat disimpulkan bahwa metode studi kasus lebih tepat digunakan untuk penelitian yang berkaitan dengan bagaimana dan kenapa.

- Informan Kunci: Natasha selaku Marketing Colourfun Booth memiliki tugas mengikuti kebutuhan dan keinginan konsumen, merencanakan produk, menetapkan harga, dan merencanakan promosi.

- Informan Utama: Mario selaku Business Development Colourfun Booth memiliki tugas untuk melakukan riset pasar, mencari peluang pelanggan baru, dan menjaga hubungan baik dengan konsumen agar citra Colourfun Booth dapat meningkat.

- Informan Pendukung: Jessicca Carneline selaku owner Colourfun Booth memiliki tugas untuk menyusun, mengomunikasikan, dan menerapkan strategi komunikasi pemasaran visi \& misi Colourfun Booth kepada para bawahannya. Hal ini dilakukan agar dapat mencapai tujuan perusahaan.

Pada penelitian ini, peneliti menggunakan metode-metode pengumpulan data untuk memperoleh data adalah sebagai berikut:

- Wawancara: Peneliti melakukan wawancara atau tanya jawab langsung dengan narasumber yaitu Jessicca Carneline selaku owner Colourfun Booth.

- Dokumentasi: Peneliti mengumpulkan hasil gambar yang diambil saat melaksanakan wawancara dengan Jessicca Carneline selaku owner Colourfun Booth dan hasil gambar yang diambil saat event berlangsung sebagai bukti hasil kegiatan.

- Observasi: Peneliti mengamati secara langsung dengan tujuan dapat memperoleh suatu gambaran yang jelas mengenai objek penelitian.

Setelah mendapatkan data dari hasil wawancara, selanjutnya peneliti melakukan pengolahan dan analisis data dengan tiga langkah yaitu: 
- Data Reduction: Reduksi data diartikan sebagai merangkum, memilih, memfokuskan pada hal pokok yang memberikan gambaran secara menyeluruh dan mempermudah peneliti dalam melakukan pengumpulan data selanjutnya.

- Display Data: Penyajian data dalam bentuk uraian singkat, bagan, hubungan antar kategori, flowchart dan sejenisnya.

- Conclusion Drawing: Penarikan kesimpulan tahap awal yang didukung dengan bukti-bukti valid.

\section{Hasil Penelitian}

Pada dasarnya, komunikasi menjadi salah satu elemen terpenting dalam keberhasilan pencapaian usaha. Dengan komunikasi yang baik, Colourfun Booth dapat membangun hubungan baik dengan konsumen. Dengan adanya hubungan tersebut diharapkan mampu menjadi pengait antara merek dengan konsumen untuk membangkitkan loyalitas konsumen terhadap merek. Di era new normal, Colourfun Booth berusaha menangani perubahan-perubahan yang terjadi dan mengembangkan strategi komunikasi pemasaran yang tepat agar usahanya tetap dapat berdiri dan unggul dalam bersaing terutama di dalam bidang photo booth.

\section{Komunikasi Antara Colourfun Booth Dengan Konsumen}

Komunikasi yang dilakukan oleh Colourfun Booth dengan konsumen melalui dua media sosial yaitu media sosial Instagram dan Facebook. Tetapi, Colourfun Booth cenderung lebih menggunakan media sosial Instagram dibandingkan media sosial Facebook untuk membagikan informasi dan membentuk image sesuai dengan apa yang ingin ditanamkan oleh Colourfun Booth di dalam benak konsumen. Hal ini didukung dengan segmentasi pasar Colourfun Booth yaitu berusia 20-45 tahun yang diduga aktif dalam menggunakan media sosial. Maka, Colourfun Booth berusaha membangun hubungan baik dengan konsumen di era new normal yaitu melalui media sosial Instagram. Dengan cara melakukan kegiatan komunikasi melalui fitur-fitur yang disediakan oleh Instagram. Salah satu fiturnya adalah QnA (question and answer). Fitur QnA ini berfungsi untuk berinteraksi dengan konsumen yang bertujuan menciptakan pemahaman melalui pengetahuan yang diberikan.

\section{Strategi Komunikasi Pemasaran Colourfun Booth}

\section{Perencanaan Komunikasi Pemasaran Terpadu}

Perencanaan komunikasi pemasaran terpadu merupakan dasar keseluruhan komunikasi. Langkah-langkah perencanaan komunikasi pemasaran terpadu sebagai berikut:

a) Menganalisis Situasi: Colourfun Booth melakukan analisis SWOT (Strength, Weakness, Opportunity, Threat) di era new normal.

b) Mengidentifikasi Khalayak Sasaran: Colourfun Booth mengidentifikasi calon konsumen potensial yang dapat mengambil keputusan membeli.

c) Menentukan Tujuan Komunikasi Pemasaran: Bertujuan menjaga konsistensi pelaksanaan komunikasi pemasaran agar sesuai tujuan awal.

d) Menetapkan Anggaran Komunikasi Pemasaran: Colourfun Booth menyadari bahwa pelanggan dapat berubah menggunakan jasa yang disediakan oleh kompetitor. Sehingga Colourfun Booth menyediakan dan memberikan kualitas jasa yang terbaik dengan harga minimal. 
e) Mengembangkan Program Komunikasi Pemasaran: Mengembangkan alat-alat atau bauran komunikasi yang digunakan seperti periklanan, promosi penjualan, Public Relations, personal selling, dan pemasaran langsung.

\section{Pelaksanaan Komunikasi Pemasaran Terpadu}

a) Iklan

Salah satu alat yang digunakan Colourfun Booth dalam mempromosikan barang dan jasanya yaitu iklan. Iklan merupakan instrumen promosi yang penting khusunya bagi perusahaan yang memproduksi barang atau jasa. Iklan juga dapat meningkatkan citra jangka panjang bagi produk atau jasa Colourfun Booth dan dapat meningkatkan penjualan dengan cepat karena lebih efisien menjangkau pembeli yang tersebar secara geografis. Dalam hal ini, Colourfun Booth mengiklankan usahanya melalui media sosial Instagram dan Facebook.

Menurut Philip Kotler, iklan dapat meningkatkan penjualan melalui media sosial jika sesuai dengan kriteria AIDA yang digunakan sebagai pedoman dalam melakukan komunikasi pemasaran. AIDA (Attention, Interest, Desire, Action) merupakan sebuah konsep yang memegang peranan penting dalam sebuah pemasaran.

b) Logo Minimalis

Menurut Colourfun Booth, Logo memberikan simbol visual perusahaan yang mudah dikenali. Dengan menempatkan logo yang tepat maka perusahaan memberikan eksposur yang konsisten terhadap merek. Semakin konsumen terekspos dengan logo perusahaan, maka logo perusahaan akan dengan mudah melekat di dalam benak konsumen. Colourfun Booth membuat logo secara sederhana agar mudah dibaca dan diingat.

c) Celebrity Endorser

Merupakan aktor atau artis, entertainer atau dikenal secara umum atas keberhasilannya di bidangnya masing-masing untuk memberi dukungan pada produk yang diiklankan. Komunikasi pemasaran melalui endorse merupakan cara modern yang digunakan perusahaan agar produk atau jasa dapat dikenal oleh masyarakat luas dengan bantuan media sosial.

d) Public Relations

Dalam mempromosikan, Public Relations tidak hanya fokus pada manfaat dan fitur produk tetapi juga fokus pada nilai-nilai perusahaan secara keseluruhan. Nilai-nilai perusahaan ini berkaitan dengan pembentukan persepsi masyarakat mengenai Colourfun Booth atau disebut dengan citra perusahaan. Citra perusahaan dianggap sebagai kesan yang tertanam di dalam benak masyarakat mengenai produk atau jasa dari Colourfun Booth.

e) Promosi Penjualan

Colourfun Booth menggunakan promosi penjualan untuk mendorong konsumen agar tertarik untuk menggunakan jasanya. Perilaku konsumtif masyarakat biasanya meningkat saat melihat adanya potongan harga karena untuk kesenangan dan gaya hidup. Promosi penjualan yang digunakan yaitu promosi yang diarahkan kepada konsumen (consumer promotion) seperti sampel, kupon, dan potongan harga.

f) Word of Mouth

Komunikasi word of mouth adalah saluran komunikasi yang kerap digunakan oleh Colourfun Booth karena dinilai sangat efektif dan tidak perlu mengeluarkan biaya dalam melancarkan proses pemasaran. Informasi yang 
didapatkan dari komunikasi mulut ke mulut juga lebih mudah dimengerti dan lebih dipercaya oleh konsumen karena informasi tersebut berasal langsung dari orang yang memiliki pengalaman dalam menggunakan jasa Colourfun Booth.

g) Event and Experiences

Acara dan pengalaman memberikan banyak keuntungan karena konsumen dapat menilai dari proses dan harga yang Colourfun Booth berikan. Berikut masing-masing penjelasannya:

- Proses: Colourfun Booth menyediakan peralatan yang lengkap agar mendapatkan hasil yang baik dan memuaskan, memberikan paket photobooth cukup lengkap sesuai dengan perkembangan photobooth, dan photographer professional yang handal dan berpengalaman serta assistant photographer untuk membantu konsumen dalam melakukan sesi foto.

- Harga: Natasha selaku marketing serta tim Colourfun Booth Colourfun Booth telah melakukan analisis kompetitor dari segi harga hingga mengukur keberadaan kompetitor di masa mendatang. Oleh karena itu, Colourfun Booth menyediakan dan memberikan kualitas jasa yang terbaik dengan harga minimal serta hasil yang sesuai dengan yang diharapkan oleh konsumen

3. Evaluasi Komunikasi Pemasaran Terpadu

Setelah melakukan perencanaan dan pelaksanaan komunikasi pemasaran, komunikator melakukan riset apa saja dampak yang dirasakan khalayak sasaran. Pesan yang disampaikan melalui bauran promosi yang digunakan efektif dalam menjaga konsumen di era new normal. Dalam hal ini, Colourfun Booth menanyakan berapa banyak melihat pesan, apakah pesan tersebut dengan mudah diingat, informasi apa yang didapat, bagaimana tanggapan terhadap pesan dan bagaimana sikap yangdiberikan setelah mengetahui produk atau jasa dari Colourfun Booth. Komunikator mengukur perilaku yang diakibatkan oleh pesan tersebut dengan mengukur berapa banyak orang yang menggunakan jasa dari Colourfun Booth.

\section{Simpulan}

Berdasarkan hasil analisis data pada bab sebelumnya, peneliti dapat menyimpulkan bahwa Colourfun Booth mampu menjaga konsumen di era new normal.

1. Public Relations Colourfun Booth tidak hanya fokus pada manfaat dan fitur produk atau jasa melainkan menjaga hubungan baik antara Colourfun Booth dengan konsumen. Dengan cara melakukan kegiatan komunikasi melalui fitur-fitur yang disediakan oleh media sosial Instagram dan Facebook.

2. Events Experience merupakan hal yang sangat penting karena menimbulkan Word of Mouth. Informasi Word of Mouth lebih mudah dimengerti dan lebih dipercaya oleh konsumen karena informasi tersebut berasal langsung dari orang yang mempunyai pengalaman dalam menggunakan jasa Colourfun Booth.

3. Bauran Promosi yang digunakan oleh Marketing Colourfun Booth efektif dalam menjaga konsumen di era new normal. Dalam hal ini, iklan digunakan untuk memperkenalkan jasa Colourfun Booth kepada masyarakat luas.

Bagi penelitian berikutnya dapat membahas lebih dalam terutama mengenai komunikasi pemasaran terpadu. Dalam pengambilan data dengan metode observasi dapat dilakukan dengan mudah agar hasil analisis yang diperoleh komprehensif. Dan bagi Colourfun Booth dapat terus berinovasi untuk menghasilkan ide-ide baru. 
Sehingga, dapat unggul bersaing dari kompetitor lainnya di bidang yang sama yaitu photobooth.

\section{Ucapan Terima Kasih}

Peneliti mengucapkan terima kasih kepada narasumber dan seluruh pihak yang telah membantu dan mendukung proses penelitian hingga selesai, khususnya kepada Fakultas Ilmu Komunikasi Universitas Tarumanagara.

\section{Daftar Pustaka}

Facebook.com (20 Juni 2021). Diakses dari https://www.facebook.com/ColourfunBooth/posts/tksh-very-much-tocolorfunbooth-groovy-and-aston-bekasi-crew/953023131409478/

Kotler, P. \& Keller, P. K. (2012). Manajemen Pemasaran Edisi 12. Jakarta: Erlangga. Tohirin. (2013). Metode Penelitian Kualitatif Dalam Pendidikan Dan Bimbingan Konseling. Jakarta: PT Raja Grafindo Persada. 